\title{
Parent-reported feeding characteristics in children with ASD vs. children who are typically developing
}

Nesreen Fathi Mahmoud ${ }^{1 *}$, Rehab Safwat Abdelhameed ', Sherif A. Abdelmonam², Ahmed Ali Abdelmonem', Doaa Mahmoud Khalii ${ }^{3}$ and Shimaa Ahmed Saleh Bakia ${ }^{1}$

\begin{abstract}
Background: Parents of children with autism spectrum disorders (ASDs) often report that their children have multiple dietary behavior problems than parents of typically developing (TD) children do. This may affect proper nutrition and subsequently adequate growth and development in children with ASD. The current study aimed to assess the feeding behavior in recently diagnosed children with autism spectrum disorders (ASD) ranged in age from 2 to 4 years and compare it with typically developing (TD) children and to explore the relationship between feeding behaviors and autism severity using the Montreal Children's Hospital Feeding Scale (MCH) and Childhood Autism Rating Scale (CARS), respectively. Parents of 35 preschool children (2-4 years) with ASD completed reports of physical measurements, feeding interview, Childhood Autism Rating Scale (CARS), and Montreal Children's Hospital Feeding Scale (MCH Feeding-Scale). The collected data from parents of children with ASD were analyzed and compared with 70 typically developed children matched with age and sex.
\end{abstract}

Results: ASD children showed statistically significantly more problematic feeding behaviors in most of the assessed eating characters compared with TD children, e.g., food neophobia, eating non-food items instead of food, requiring assistance during eating, and feeding avoidance to particular textures and taste. The mean total score of the MCH feeding scale differed significantly between children with ASD and TD children. No correlation was found between the mean total score of the MCH feeding scale and CARS scores.

Conclusion: Our findings revealed a high rate of behavioral feeding problems in children with ASD. Future work will be needed to follow up the feeding behaviors and to develop practical feeding approaches for ASD children to maintain nutritional adequacy.

Keywords: Parents, Feeding, Children, Autism

\footnotetext{
* Correspondence: Nesreen.hussien@med.bsu.edu.eg;

Nosnos_1981@yahoo.com

${ }^{1}$ Phoniatrics Unit-Department of ENT, Faculty of Medicine, Beni-Suef

University, Beni-Suef, Egypt

Full list of author information is available at the end of the article
}

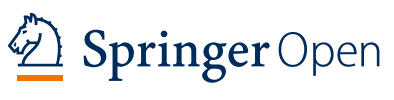

(c) The Author(s). 2021 Open Access This article is licensed under a Creative Commons Attribution 4.0 International License, which permits use, sharing, adaptation, distribution and reproduction in any medium or format, as long as you give appropriate credit to the original author(s) and the source, provide a link to the Creative Commons licence, and indicate if changes were made. The images or other third party material in this article are included in the article's Creative Commons licence, unless indicated otherwise in a credit line to the material. If material is not included in the article's Creative Commons licence and your intended use is not permitted by statutory regulation or exceeds the permitted use, you will need to obtain permission directly from the copyright holder. To view a copy of this licence, visit http://creativecommons.org/licenses/by/4.0/. 


\section{Background}

Parents of children with autism spectrum disorders (ASDs) often report that their children have multiple dietary behavior problems than parents of typically developing (TD) children do [1-3]. This may affect proper nutrition and subsequently adequate growth and development in children with ASD.

Earlier studies demonstrated a wide prevalence range of feeding problems in ASD children extending from 13 to $80 \%$ [4]. More recently, Nadon et al. [5] stated that $80 \%$ of children with ASD experience-feeding problems. Results by Seiverling et al. [6] supported that children with ASD in early age have significantly more feeding problems with special concern to food selectivity than typically developed ones.

Food selectivity, as described by parents of children with ASD, includes picky eating, frequent food refusals, mealtimes' rituals, limited repertoires of foods [4], and selective intake of certain food categories, such as carbohydrates [7], uniform food preferences, and unusual feeding behaviors $[8,9]$. The prevalence estimates of selective food acceptance in children with ASD vary, but researchers have consistently found that more than half of children with ASD exhibit limited food acceptance [4, 10, 11].

Food refusal may be caused by a variety of reasons, including smell, texture, and color [4]. Aversions to certain textures as well as eating inedible objects have been reported [12]. Behaviors such as consuming more salty and sugary foods, refusal of fruits, and vegetables are considered the most important factors that reduce the nutritional value [13].

The unclear nomenclature of feeding and eating problems in children with ASD makes it difficult to determine whether such problems are attributed to autism traits or a separate diagnosis. Several factors may contribute to the development and persistence of eating problems. These factors included the autism traits attribution, the underlying genetic vulnerability that interacted with environmental factors, or underlying difficulties in cognitive, social, and/or emotional functioning [14-16]. Brede et al. (2020) [17] linked sensory sensitivities, social difficulties, and emotional difficulties to restrictive food intake in children with ASD.

It was hypothesized that feeding difficulties are common in children with autism [6], but a vast majority of studies investigated this issue in older children $[3,4,7$, 8]. Few recent studies have urged that feeding problems begin early at a young age in children with ASD $[6,18-$ 20].

Recent guidelines recommend starting an integrated behavioral and developmental behavioral intervention as soon as ASD diagnosis is settled [19]. As early as 2 or 3 years of age, a child's brain is still forming [20], and more "plastic" than at older ages. Early identification of and intervention for feeding problems in autism could be advantageous because of the brain's plasticity in this age range.

Additionally, the first required step to initiate a positive change in children's eating behavior lies in communicating the knowledge between professionals and parents [21]. The use of parental reports of foods eaten and behaviors related to eating in the chosen target age may guide professionals to create an alternative feeding strategy for early intervention that goes hand in hand with other core autism behavior rehabilitation.

In summary, there is a lack of research on feeding behavior problems in children recently diagnosed with ASD and hardly any research work has been reported from Egypt. This has important implications not only for diagnostic purposes but also for the potential intervention. Therefore, the first purpose of this study was to compare the general problematic feeding behaviors of children with ASD and TD children such as food selectivity, food neophobia, eating non-food items instead of food, and ritualistic feeding behaviors, that are experienced by these two groups using a sample of recently diagnosed children with ASD who were not referred to nutritional clinics before, and using a matched control group of TD children with restricted age range (2-4 years). The second purpose was to explore the relationship between feeding behavior and autism severity using the Montreal Children's Hospital Feeding Scale (MCH) and Childhood Autism Rating Scale (CARS) scores as an indicator of feeding behaviors difficulties and autism severity in children with ASD, respectively.

\section{Methods}

Ethics

Before starting the study, all parents were informed of the study protocol by the nurse coordinator, and written informed consent was obtained. The study was approved by the Ethics Committee No: FMBSUREC/03112019/ Abdelhameed.

\section{Participants}

A cross-sectional, case-control observational study was conducted between January 2020 and April 2020. At first, 150 children agreed to take part in the study: 50 in the case group (children with ASD) and 100 controls (typically developing, TD). The selection criteria of the case group: (1) All the children in the case group were 2-4 years of age and were recruited to the outpatient clinic of Phoniatrics Unit. (2) The diagnosis of ASD was performed by a multidisciplinary team (composed of a senior child psychiatrist, a phoniatrician, and an experienced child psychologist), which was confirmed by evaluation of DSM-V criteria [22], and administration of 
the Childhood Autism Rating Scale (CARS) (Arabic version) [23]. (3) Children with ASD performed also some recommended laboratory tests and assessments to rule out any other medical conditions, including audiometry, assessment of thyroid function, cerebral palsy or other neurological disorder, known genetic or chromosomal abnormality, and severe visual or hearing impairment. In addition, children with food allergies or on medications which may modify dietary intake were excluded from the study. (4) All children with ASD were recently diagnosed with autism by previous measures (DSM-V \& CARS) within 2 weeks before they were invited to participate in the study.

The control group was recruited from preschool nurseries. They were matched to the ASD group for age and gender. In addition to the previously mentioned above exclusion criteria for the ASD group, exclusion criteria for TD children were (a) no parental concern about their children motoric development, no complaints of language or speech disorders, no prior speech therapy, and adequate performance in the Modified Preschool Language Scale [24]. (b) TD children did not demonstrate significant difficulties with social (eye contact, lack of social interaction) or repetitive behaviors.

Finally, due to failure to receive or complete the questionnaires, 15 and 30 children were excluded from the case and control groups, respectively. The final sample consisted of 105 children: 35 with ASD (case group) and 70 with TD (control group).

All participants completed one study visit during which demographic information was collected (Vineland Adaptive Behavior Scales score, CARS, birth weight, number of children in family, mother's average age), body mass index (BMI) was measured, and the parents/ mothers from both groups were asked to complete a feeding interview questionnaire and the Montreal Children's Hospital Feeding Scale (MCH-Feeding Scale) [25] after a brief explanation for describing their children feeding behavior over the previous 6 months before the study.

\section{Procedures}

\section{Childhood Autism Rating Scale (CARS) (Arabic version) [23]}

CARS is the most widely used standardized behavioral rating scale of autistic characteristics in children over the age of two. The CARS includes 14 domains for assessing autism-related behaviors, such as imitation, verbal and nonverbal communication, emotional responsiveness, body and object use, and intellectual and activity levels. The 15th domain rates the general impression of autism. Each domain is scored on a scale ranging from one to four, with higher scores indicating a higher level of impairment. Total scores can range from a low of 15 to a high of 60; scores less than 30 indicate that the individual is not autistic, scores between 30 and 36.5 indicate mild to moderate autism, and scores from 37 to 60 indicate severe autism [26].

\section{Semi-structured feeding interview}

Participants completed an open-ended and closed-ended feeding interview (yes or no). For answering questions related to types of food preference, parents were given a choice of three descriptions: no, some, or all. The physician defined the previous answers to provide parents with a reliable way to describe their child's food preference (no defined as no item selected in this food category), some (one or two items selected), and all (three or more items selected). The interview questions investigated general eating, chewing, choking, and swallowing behaviors as well as feeding therapy, and included questions, e.g., about food neophobia, eating non-food items, use of special diets, and whether their child currently or in the past year refused foods based on different characteristics, such as texture, color, and taste. The feeding interview was developed and is based on previous research on behavioral feeding difficulties experienced in children $[27,28,29]$.

\section{Montreal Children's Hospital Feeding Scale (MCH-Feeding Scale) [25]}

Items for $\mathrm{MCH}$-Feeding Scale targeted at children aged 6 months to 6 years. The scale included 14 items that covered various feeding domains, with some items that were common overlap, including oral motor (items 8 and 11), oral sensory (items 7 and 8), and appetite (items 3 and 4). Other items addressed maternal concerns about feeding (items 1, 2, and 12), mealtime behaviors (items 6 and 8), maternal strategies used (items 5, 9, and 10 ), and family reactions to their child's feeding (items 13 and 14). Each item is rated on a seven-point Likert scale with the anchor points at either end. Seven items are scored from negative to positive direction, and the remaining seven from positive to negative direction. The parent/caregiver marks each item according to the frequency of a feeding behavior. After reversing the scores of seven items from negative to positive, the total feeding problem score is calculated by adding the scores for each item.

\section{Statistical analysis}

Statistical Package for Social Science (SPSS v. 25) was used to analyze interview questions and questionnaire scores. The quantitative variables were described using the form of the mean and standard deviation (SD). The description of qualitative variables was in the form of numbers (No.) and percentage (\%). Data were explored for normality using the Kolmogorov-Smirnov test. A chi-squared test was used to compare cases and controls 
regarding the categorical variables. $T$ test was used to compare cases and controls regarding the normally distributed scale variables, and Mann-Whitney test was used for non-normally distributed data. The significance of the results was determined in the form of a $P$ value that was classified into non-significant when $P$ value > 0.05 and significant when a $P$ value $\leq 0.05$.

The power of sample size was estimated using g*power software based on the effect size of 0.5 , overall type I error rate $(\alpha) \leq 0.05$. One hundred five subjects (35-case, 70-control) are expected to achieve a power of more than $80 \%$.

\section{Results}

\section{Demographic information of the children that} participated in the study

Records of 105 subjects who participated in the current study were analyzed. All subjects had growth parameters and completed the feeding interview and $\mathrm{MCH}$ feeding scale. Subjects ranged from 2 to 4 years. The sample included 35 children with ASD (26 boys (74.3\%), 9 girls (25.7\%)), 70 TD children (39 boys (55.7\%), and 31 girls (44.3\%)). Table 1 presented the participants' characteristics. The age and sex of the two groups showed no statistically significant difference. No statistically significant difference was found between both groups in the following variables: birth weight, number of children in a family, and mother's mean age. Regarding children with ASD, the majority (85\%) of parents reported that their children with ASD were born at full term with no significant differences between the groups. Birth weight and mother's average age at the child's birth were comparable for the two groups with no significance between the groups. The median number of children in the families was similar across both groups (3 and 4 children per family of children with ASD, family of TD children, respectively). The vast majority of the questionnaires were completed by the mother (mother: 97.5\%; father: $2.5 \%$ ) of the child in question, and $60 \%$ had a university degree or higher qualification. Children with ASD had a statistically significant higher BMI than TD children ( $P$ value $<0.001)$. According to the data obtained from autism severity measured by total CARS scores, it revealed 30 children with ASD in mild/moderate, and 5 children were rated as a severe degree.

\section{Group differences in eating behavior obtained from parents' interview}

Regarding feeding interviews, parents' reports of their children's most common eating and swallowing characteristics were presented in Tables 2 and 3, which revealed that children with ASD differed significantly in almost all variables compared with TD children. Children with ASD had significantly special types of food selectivity than the TD children. All children in both groups preferred juice and starch at similar rates. Children with ASD were exhibiting neophobic eating behaviors more than the TD children. Children with ASD significantly preferred to eat non-food items instead of food rather than the TD children did. ASD experienced a significantly greater percentage of problems in selffeeding skills $(71.4 \%)$ than the TD children. Parents of TD children had a greater ability to control their child's feeding behaviors over their feeding situation than parents of children with ASD do.

Also, children with ASD showed insignificantly higher rates of ritualistic feeding behaviors than TD children. Children with ASD were more likely to avoid particular textures or tastes than the TD children. $94.3 \%$ of children with ASD significantly showed an aversion to strong textures (i.e., hard, solid consistency) and strong tastes (i.e., concentrated flavor, hot, and spicy) and

Table 1 Demographic characteristic of children with autism ASD and TD children

\begin{tabular}{llll}
\hline & Children with ASD $(\boldsymbol{n}=\mathbf{3 5})$ & TD children $(\boldsymbol{n}=\mathbf{7 0})$ & \multicolumn{1}{c}{$\boldsymbol{P}$ value } \\
\hline Age $($ years $)(\mathrm{M} \pm \mathrm{SD})$ & $3.3 \pm 0.64$ & $2-4$ \\
Age range (years) & $2-4$ & \\
Sex $n(\%)$ & & $39(55.7 \%)$ \\
Males & $26(74.3 \%)$ & $31(44.3 \%)$ \\
Females & $9(25.7 \%)$ & $20.1 \pm 1.6$ \\
BMI $(M \pm S D)$ & $22.2 \pm 2.3$ & $\mathrm{~N} / \mathrm{A}$ \\
Vineland Adaptive Behavior Scales score $(\mathrm{M} \pm \mathrm{SD})$ & $100.68 \pm 16.52$ & $\mathrm{~N} / \mathrm{A}$ \\
CARS $(M \pm S D)$ & $33.24 \pm 2.24$ & $3.43 \pm 1.2$ \\
Birth weight & $3.25 \pm 1.1$ & 4 \\
Number of children in family (median) & 3 & $36.2 \pm 6.5$ \\
Mother's average age & $35.5 \pm 5.9$ & $<0.001$ \\
\hline
\end{tabular}

$N / A$ not applicable

$M$ mean, $S D$ standard deviation 
Table 2 Eating characteristics of children with ASD and TD children

\begin{tabular}{|c|c|c|c|c|c|c|}
\hline & & \multicolumn{2}{|c|}{$\begin{array}{l}\text { Children with ASD } \\
\text { Count }(\%)(n=35)\end{array}$} & \multicolumn{2}{|c|}{$\begin{array}{l}\text { TD children } \\
\text { Count }(\%)(n=70)\end{array}$} & \multirow[t]{2}{*}{$\begin{array}{l}P \\
\text { value }\end{array}$} \\
\hline & & Yes & No & Yes & No & \\
\hline \multicolumn{2}{|l|}{ Q1a: Does your child prefer special types of food? } & $33(94.3 \%)$ & $2(5.7 \%)$ & $32(45.7 \%)$ & $38(54.3 \%)$ & $<0.001$ \\
\hline \multicolumn{2}{|l|}{ Q1b: Does your child feel food neophobia? } & $32(91.4 \%)$ & $3(8.6 \%)$ & $4(5.7 \%)$ & $66(94.3 \%)$ & $<0.001$ \\
\hline \multicolumn{2}{|l|}{ Q1c: Does your child ever prefer to eat non-food items instead of food? } & $15(42.9 \%)$ & $20(57.1 \%)$ & $2(2.9 \%)$ & $68(97.1 \%)$ & $<0.001$ \\
\hline \multicolumn{2}{|l|}{ Q1d: Does your child require any assistance during the eating process? } & $25(71.4 \%)$ & $10(28.6 \%)$ & $36(51.4 \%)$ & $34(48.6 \%)$ & 0.047 \\
\hline \multicolumn{2}{|l|}{$\begin{array}{l}\text { Q1e: Do you report any ritualistic feeding behaviors in your child } \\
\text { (e.g., person, place, and utensil? }\end{array}$} & $11(31.4 \%)$ & $24(68.6 \%)$ & $14(20 \%)$ & $34(48.6 \%)$ & 0.195 \\
\hline \multirow{4}{*}{$\begin{array}{l}\text { Q1f: Does your child display any oral aversion to oral feeding } \\
\text { (i.e., not accepting the bottle, cup or spoon), avoiding particular } \\
\text { textures or taste, color? }\end{array}$} & Oral feeding & $8(22.9 \%)$ & 27 (77.1\%) & $18(25.7 \%)$ & $52(74.3 \%)$ & 0.749 \\
\hline & Strong Texture & 33 (94.3\%) & $2(5.7 \%)$ & $5(7.1 \%)$ & 65 (92.9\%) & $<0.001$ \\
\hline & Strong Taste & 33 (94.3\%) & $2(5.7 \%)$ & 16 (22.9\%) & $54(77.1 \%)$ & $<0.001$ \\
\hline & color & 8 (22.9\%) & 27 (77.1\%) & 18 (25.7\%) & 52 (74.3\%) & 0.749 \\
\hline
\end{tabular}

similarly, $94.3 \%$ of children with ASD showed eating challenges with solid texture (Table 2).

Table 3 illustrated that on comparison of special types of food preference between children with ASD and TD children, no statistical significant difference was found.

Next, the data obtained from the subsequent subscales of the feeding interview: chewing, choking, swallowing, and feeding therapy characteristics of children with ASD and TD children were analyzed and no statistically significant difference was found between both groups under the study in each subscale as illustrated in Table 4.

\section{Comparison of ASD and TD by MCH-scale}

Further examination of the data obtained from different domains of the $\mathrm{MCH}$-scale revealed a statistically significant difference between both groups in the mealtime domain and maternal strategies used; otherwise, no statistical significant differences were found in other domains as shown in Table 5.

As far as the severity of ASD is concerned, no statistical significant correlation was found between the total score of $\mathrm{MCH}$ feeding scale and total CARS scores as shown in Table 6.

Table 3 Comparison of special types of food preference (selectivity) (fruits/vegetables/meat/milk product/juice/starch) among ASD children and TD children

\begin{tabular}{|c|c|c|c|c|}
\hline Food type & & Children with ASD count $(\%)(n=35)$ & TD children count $(\%)(n=70)$ & $P$ value \\
\hline \multirow[t]{3}{*}{ Fruits } & No & $4(12.1 \%)$ & $0(0.0 \%)$ & 0.034 \\
\hline & some & $15(45.5 \%)$ & $23(71.9 \%)$ & \\
\hline & All & $14(42.4 \%)$ & $9(28.1 \%)$ & \\
\hline \multirow[t]{3}{*}{ Vegetables } & No & $2(6.1 \%)$ & $2(6.3 \%)$ & 0.995 \\
\hline & some & $20(60.6 \%)$ & $19(59.4 \%)$ & \\
\hline & All & $11(33.3 \%)$ & $11(33.4 \%)$ & \\
\hline \multirow[t]{3}{*}{ Meat } & No & $8(24.2 \%)$ & $1(3.1 \%)$ & 0.038 \\
\hline & some & 19 (57.6\%) & $21(65.6 \%)$ & \\
\hline & All & $6(18.2 \%)$ & $10(31.3 \%)$ & \\
\hline \multirow[t]{3}{*}{ Milk products } & No & $3(9.1 \%)$ & $1(3.1 \%)$ & 0.488 \\
\hline & some & $18(54.5 \%)$ & $16(50.0 \%)$ & \\
\hline & All & $12(36.4 \%)$ & $15(46.9 \%)$ & \\
\hline \multirow[t]{3}{*}{ Juice } & No & $0(0.0 \%)$ & $0(0.0 \%)$ & 0.316 \\
\hline & some & 15 (46.9\%) & 19 (59.4\%) & \\
\hline & All & 17 (53.1\%) & $13(40.6 \%)$ & \\
\hline \multirow[t]{3}{*}{ Starch } & No & $0(0.0 \%)$ & $0(0.0 \%)$ & 0.244 \\
\hline & some & 11 (35.5\%) & $16(50.0 \%)$ & \\
\hline & All & $20(64.5 \%)$ & $16(50.0 \%)$ & \\
\hline
\end{tabular}


Table 4 Chewing, choking, swallowing, and feeding therapy characteristics of children with ASD and TD children

\begin{tabular}{|c|c|c|c|c|}
\hline & \multicolumn{2}{|c|}{$\begin{array}{l}\text { Children with ASD } \\
\text { Count }(\%)(n=35)\end{array}$} & \multicolumn{2}{|c|}{$\begin{array}{l}\text { TD children } \\
\text { count }(\%)(n=70)\end{array}$} \\
\hline & Yes & No & Yes & No \\
\hline Q2: Does your child have any eating challenges with food textures? & $33(94.3 \%)$ & $2(5.7 \%)$ & $5(7.1 \%)$ & $65(92.9 \%)$ \\
\hline Q3: Has your child ever experienced choking while feeding? & $0(0 \%)$ & $35(100 \%)$ & $0(0 \%)$ & $70(100 \%)$ \\
\hline $\begin{array}{l}\text { Q4: Has your child ever experienced any swallowing difficulties during } \\
\text { eating throughout your child's life? }\end{array}$ & $0(0 \%)$ & $35(100 \%)$ & $0(0 \%)$ & $70(100 \%)$ \\
\hline $\begin{array}{l}\text { Q5a: Has your child received any therapy from a speech-language } \\
\text { pathologist for eating issues? }\end{array}$ & $0(0 \%)$ & $35(100 \%)$ & $0(0 \%)$ & $70(100 \%)$ \\
\hline $\begin{array}{l}\text { Q5b: Has your child received any therapy from a psychologist for } \\
\text { eating issues? }\end{array}$ & $0(0 \%)$ & $35(100 \%)$ & $0(0 \%)$ & $70(100 \%)$ \\
\hline $\begin{array}{l}\text { Q5c: Has your child undergone any surgeries to better manage } \\
\text { his/ her swallowing or eating? }\end{array}$ & $0(0 \%)$ & $35(100 \%)$ & $0(0 \%)$ & $70(100 \%)$ \\
\hline
\end{tabular}

\section{Discussion}

Most of the previous studies examined behavioral feeding problems in children with ASD considering across a wide age range, whereas our study paid attention to recently diagnosed children with ASD aged from 2 to 4 years to enhance early detection and intervention of feeding problems in this particular group of children to improve their outcomes. This study tried expanding the research in this particular age of this population in three important ways: First, it compared the general eating and feeding behaviors of children with ASD and TD children who were matched in age and sex. Second, it provided an in-depth description of the food selectivity of children with ASD to that of TD children. Third, it tried to find a correlation between autism severity (total CARS scores) with the severity of feeding problems (MCH feeding scores).

Our findings implied that parents of children with ASD reported that their children exhibited more general feeding problems including food neophobia and eating strong texture and taste foods. These data are demonstrated in the following order, the most frequently reported eating behavior problems in children with ASD were food selectivity (94.3\%), food neophobia (91.4\%), requiring any assistance during the eating process (71.4\%), eating non-food items instead of food (42.9\%), and ritualistic feeding behaviors (31.4\%).
Definition of atypical eating behavior remained broad. It was defined as food refusal, selectivity, or mealtime rituals [9]. We concluded that children with ASD had a significantly higher degree of food selectivity than TD children. Across all food groups we examined, children with ASD ate fewer types of foods than did TD children. In this study, food acceptance was determined and categorized as no (zero food selected), some (one or two), or all (three or more), depending upon the number of types of food the child chose. Our results revealed that meat is the least preferable type of food. Shmaya et al. [30] referred to the poor intake of calcium, and protein in children with ASD is less than TD children which affects later the nutrient required for growing and development.

Pica is also referred to atypical food behavior as children with ASD prefer to eat non-food items instead of food (i.e., objects, rocks, or dirt). Parents of children with ASD frequently describe their children as "picky eaters," refusing to try or eat a variety of foods. Pica in children with ASD may be even more restrictive and may extend beyond the early childhood period [31-33].

We reported some of the factors, which influence food selectivity: texture $(94.3 \%)$, taste $(94.3 \%)$, and color (22.9\%). Several studies have consistently identified food texture as a related aspect of food acceptance [34-36].

Food selectivity may result in inadequate weight gain, simply because children with ASD consume more

Table 5 The feeding domains covered by MCH feeding scale in both groups understudy

\begin{tabular}{|c|c|c|c|}
\hline Domains & Children with ASD $(n=35)$ & $\begin{array}{l}\text { TD children } \\
(n=70)\end{array}$ & $P$ value \\
\hline Oral motor & $7.6286 \pm 1.39507$ & $7.5294 \pm 1.09913$ & 0.694 \\
\hline Oral sensory & $7.4286 \pm 1.19523$ & $7.4118 \pm 1.44796$ & 0.953 \\
\hline Appetite & $9.7143 \pm 3.30393$ & $9.8824 \pm 3.86152$ & 0.827 \\
\hline Maternal concerns about feeding & $14.0857 \pm 1.61558$ & $14.0882 \pm 1.97549$ & 0.995 \\
\hline Mealtime behaviors & $9.5714 \pm 2.09039$ & $8.3235 \pm 2.06926$ & 0.005 \\
\hline Maternal strategies used & $9.7429 \pm 2.35575$ & $8.0294 \pm 2.87537$ & 0.003 \\
\hline Family reactions to their child's feeding & $7.9429 \pm 0.33806$ & $7.9706 \pm 0.17021$ & 0.580 \\
\hline
\end{tabular}


Table 6 Correlation between the CARS scores and the total score of the $\mathrm{MCH}$ feeding scale for children with ASD

\begin{tabular}{llll}
\hline ASD group & & T-score & Row score \\
\hline CARS & Pearson Correlation & -.011 & -.043 \\
& Sig. (2-tailed) & .952 & .808 \\
& $\mathrm{~N}$ & 35 & 35
\end{tabular}

sweetened juice and starch meals and consume less meat, fruits, and vegetables than TD children. This may be a direct cause for the significant difference in BMI between the two groups since BMI is higher in children with ASD. Many studies have revealed that the frequency of overweight and obesity in children with ASD is greater [37, 38].

In fact, altered BMI could be of multifactorial origin. A recent study found that the difference in BMI between ASD and TD children may be associated to both oral health problems and food hyperselectivity [8].

In addition to the importance of food selectivity, mealtime behavior problems and maternal strategies used were frequently observed in children with ASD [9]. Our comparative analysis revealed a significant difference in evaluating mealtime behavior between both groups under the study. This is consistent with the findings of Castro et al. (2016) [39], and Malhi et al. (2017) [40], who assessed mealtime behavior and got similar results, which entailed that children with ASD had more problems at mealtimes than the controls. It is worth noting that previous studies used different assessment tools; the first study used the Behavioral Pediatric Feeding Assessment Scale (BPFA), and the second used the Children's Eating Behavior Inventory (CEBI).

It was suggested $[41,42]$ that poor multi-sensory processing and executive function difficulties (lack of planning, e.g., washing hands, and coordinating eating) that affects activity level, emotional, and social responses may impact functional daily activities, including mealtimes can cause behavior problems in individuals with ASD who are unable to describe their distress. This issue, which may be food selectivity-based, creates stress and negatively affect family mealtimes and quality of life [43-45]. In contrast, no significant differences in mealtime behavioral problems (oral sensitivity, mild eating problems, or mild resistance to the introduction of new foods) have been reported between children with and without ASD [46].

As evidenced by our findings, children with ASD are significantly more likely to avoid foods, exhibit food neophobic behaviors, and have poorer self-feeding skills. This is consistent with previous studies in this area $[4,11]$.

Although parents of children with ASD in our sample reported that their children are highly significantly selective eaters of certain food categories such as carbohydrates (starch) with limited repertoires of food acceptance and picky eating but no parent of a child with ASD expressed a concern for referral for nutritional therapy. This may be due to a lack of awareness of essential nutritional requirements as well as the previously mentioned behavioral feeding problems which may lead to certain dietary inadequacy. According to our sample, significantly higher BMI in ASD children may mislead the parents with the feeding behaviors and probability of nutritional deficiencies in their children. Also, the recent diagnosis of their siblings and therapy plan is mainly directed towards the rehabilitation of other affected areas in autism as rehabilitation of communication and social skills.

In the current study, most items in the $\mathrm{MCH}$ scale which showed a significant difference were related mainly to the parents and their experience toward their children such as the breakdown in mealtime behaviors and maternal strategies. Our findings were in accordance with previous studies by Malhi [40] and Johnson [47] who reported elevated stress associated with mealtime in parents of ASD children. Parents' stress may be due to children's lack of reciprocity to their parents and children's disruptive acts, especially in public areas. These behaviors may cause their lack of ability to control their children and so hinder family interactions with others.

Finally, feeding problems were unrelated to autism severity by measures of CARS scores. It was difficult to draw a conclusion about the relation of feeding problems in children with the ASD and severity of autism due to the conflicting reports. Some studies suggesting that it is related to children with autism [4] while others refute this claim [48].

However, our finding could be partly explained by differences in behavioral feeding problems definitions, as well as in ASD severity evaluation tools. We investigated this topic through the CARS scale-specific for ASD, which was found as a reliable indicator of ASD severity. A recent study by Malhi et al. [49] examined the relation between the severity of autism and various behavior feeding problems such as atypical food preferences in children with ASD. They suggested that there is variability even among the ASD group, and the clinically severe ASD cases may be at a higher risk for nutritional inadequacies and growth failure.

Limitations in our study should be considered, which included a small sample size. Our main limitation was that the collected data relied on parental reports. This may result in overestimation or underestimation of problematic behaviors. The parents frequently questioned how they should answer questions about eating fruits, vegetables, and meats. This calls into question the number of uncertainties encountered by parents completing the questionnaires without assistance. 
Also, questions concerned with food refusal are based on the parent's understanding of the dominant character of the food. It is difficult for parents to report the true reason for refusal (color vs taste vs texture) because the children cannot express the reason and some foods have similar properties. For example, some parents reported that their children refused vegetables because of their color; however, other factors such as texture may play a role in the refusal. We tried to clarify this by adding a separate question in the chewing section of the feeding questionnaire asking the parents whether their children experienced eating challenges with food textures: liquids, purees, and solids.

Since our sample of children with ASD was diagnosed at a young age, this allows for a follow-up to study if the eating problems are transient or, to some extent. Future studies with a larger sample size should focus on alternative assessment methods as objective measures of food selectivity with valid dietary pattern measures including the assessment of iron deficiency, vitamin D, calcium, and zinc. More importantly, future research should focus on the relationship between dietary intake and gastrointestinal symptoms in children with ASD, as food selectivity may be significant and cause or worsen GI symptoms such as constipation. Multidisciplinary programs to overcome and follow-up on feeding difficulties need to be developed as early as the diagnosis is established to maintain nutritional adequacy since these problems are described in early childhood with the evaluation of the effects of early intervention on later development.

\section{Conclusions}

This study describes the behavior-feeding problems in children with ASD with clear differences between them and TD children. Our findings point to the importance of early investigation of feeding behaviors and the development of practical feeding approaches to maintain nutritional adequacy for children with ASD.

\section{Abbreviations}

ASD: Autism spectrum disorders; TD: Typically developed children; MCH: The Montreal Children's Hospital Feeding Scale; CARS: Childhood Autism Rating Scale; BMl: Body mass index

\section{Acknowledgements}

None

\section{Authors' contributions}

NF provided the concept, design, manuscript preparation, and manuscript editing. RS performed the research methodology, data collection, and data analysis. SA contributed to the supervision and study design. AA contributed to the supervision and methodology. DM contributed to the interpretation of the results. SS contributed to the supervision, study design, and methodology. All authors discussed the results and contributed to the writing and revising of the manuscript. The authors have approved the final manuscript.

\section{Funding}

The authors did not receive support from any organization for the submitted work.

\section{Availability of data and materials}

The datasets used and/or analyzed during the current study are available from the corresponding author on reasonable request.

\section{Declarations}

\section{Ethics approval and consent to participate}

The study was approved by the Ethics Committee of Beni-Suef University (Beni-Suef, Egypt) No: FMBSUREC/03112019/Abdelhameed. Written informed consent was obtained from all parents of participants included in the study.

Consent for publication

Not applicable

\section{Competing interests}

The authors declare that they have no competing interests.

\section{Author details}

${ }^{1}$ Phoniatrics Unit-Department of ENT, Faculty of Medicine, Beni-Suef University, Beni-Suef, Egypt. ${ }^{2}$ Department of ENT, Faculty of Medicine, Beni-Suef University, Beni-Suef, Egypt. ${ }^{3}$ Public Health and Community Medicine Department, Faculty of Medicine, Beni-Suef University, Beni-Suef, Egypt.

Received: 8 April 2021 Accepted: 7 August 2021

Published online: 22 October 2021

\section{References}

1. Funda Aslan RN (2018) Determination of nutritional behaviors of children with and without autism spectrum disorder and supplementary practices of parents. Int J Caring Sci 11(2):759-767

2. Sharp WG, Burrell TL, Jaquess DL (2014) The autism MEAL plan: a parenttraining curriculum to manage eating aversions and low intake among children with autism. Autism. 18(6):712-722. https://doi.org/10.1177/13623 61313489190

3. Lockner DW, Crowe TK, Skipper BJ (2008) Dietary intake and parents' perception of mealtime behaviors in preschool-age children with autism spectrum disorder and in typically developing children. J Am Diet Assoc 108(8):1360

4. Schreck KA, Williams K, Smith AF (2004) A comparison of eating behaviors between children with and without autism. J Autism Dev Disord 34(4):433438. https://doi.org/10.1023/B:JADD.0000037419.78531.86

5. Nadon G, Feldman DE, Dunn W, Gisel E (2011) Mealtime problems in children with autism spectrum disorder and their typically developing siblings: a comparison study. Autism. 15(1):98-113. https://doi.org/10.11 $77 / 1362361309348943$

6. Seiverling L, Towle P, Hendy HM, Pantelides J (2018) Prevalence of feeding problems in young children with and without autism spectrum disorder: a chart review study. J Early Interv 40(4):335-346. https://doi.org/10.1177/1053 815118789396

7. Cermak SA, Curtin C, Bandini LG (2010) Food selectivity and sensory sensitivity in children with autism spectrum disorders. J Am Diet Assoc 110(2):238-246. https://doi.org/10.1016/j.jada.2009.10.032

8. Bowers $L$ (2002) An audit of referrals of children with autistic spectrum disorder to the dietetic service. J Hum Nutr Diet 15(2):141-144. https://doi. org/10.1046/j.1365-277X.2002.00345.x

9. Ahearn WH (2002) Effect of two methods of introducing foods during feeding treatment on acceptance of previously rejected items. Behav Interv 17(3):111-127. https://doi.org/10.1002/bin.112

10. Ahearn WH, Castine T, Nault K, Green G (2001) An assessment of food acceptance in children with autism or pervasive developmental disordernot otherwise specified. J Autism Dev Disord 31(5):505-511. https://doi. org/10.1023/A:1012221026124

11. Leader G, Tuohy E, Chen JL, Mannion A, Gilroy SP (2020) Feeding problems, gastrointestinal symptoms, challenging behavior and sensory issues in children and adolescents with autism spectrum disorder. J Autism Dev Disord 18:1 
12. Martins Y, Young RL, Robson DC (2008) Feeding and eating behaviors in children with autism and typically developing children. J Autism Dev Disord 38(10):1878-1887. https://doi.org/10.1007/s10803-008-0583-5

13. Bandini LG, Anderson SE, Curtin C, Cermak S, Evans EW, Scampini R, Maslin M, Must A (2010) Food selectivity in children with autism spectrum disorders and typically developing children. J Pediatr 157(2):259-264. https://doi.org/10.1016/j.jpeds.2010.02.013

14. Baraskewich J, von Ranson KM, McCrimmon A, Mc Morris CA (2021) Feeding and eating problems in children and adolescents with autism: a scoping review. Autism. 2:1362361321995631

15. Mayes SD, Zickgraf H, Baweja R (2018) Unusual eating patterns and food preferences in children with ASD, ADHD, other disorders, and typical development. J Am Acad Child Adolesc Psychiatry 57(10):S157-S158. https://doi.org/10.1016/j.jaac.2018.09.082

16. Davies H, Wolz I, Leppanen J, Fernandez-Aranda F, Schmidt U, Tchanturia K (2016) Facial expression to emotional stimuli in non-psychotic disorders: a systematic review and meta-analysis. Neurosci Biobehav Rev 64:252-271. https://doi.org/10.1016/j.neubiorev.2016.02.015

17. Brede J, Babb C, Jones C, Elliott M, Zanker C, Tchanturia K, Serpell L, Fox J, Mandy W (2020) For me, the anorexia is just a symptom, and the cause is the autism: investigating restrictive eating disorders in autistic women. J Autism Dev Disord 50(12):4280-4296. https://doi.org/10.1007/s10803-02004479-3

18. Ashley K, Steinfeld MB, Young GS, Ozonoff S (2020) Onset, trajectory, and pattern of feeding difficulties in toddlers later diagnosed with autism. J Dev Behav Pediatr 41(3):165-171. https://doi.org/10.1097/DBP.0000000000000757

19. Zwaigenbaum L, Bauman ML, Choueiri R, Kasari C, Carter A, Granpeesheh D, Mailloux Z, Roley SS, Wagner S, Fein D, Pierce K (2015) Early intervention for children with autism spectrum disorder under 3 years of age: recommendations for practice and research. Pediatrics 136(Supplement 1): S60-S81

20. Dawson G, Rogers S, Munson J, Smith M, Winter J, Greenson J, Donaldson A, Varley J (2010) Randomized, controlled trial of an intervention for toddlers with autism: the Early Start Denver Model. Pediatrics. 125(1):e17e23. https://doi.org/10.1542/peds.2009-0958

21. DeCosta P, Møller P, Frøst MB, Olsen A (2017) Changing children's eating behaviour-a review of experimental research. Appetite. 113:327-357. https:// doi.org/10.1016/j.appet.2017.03.004

22. American Psychiatric Association (2013) Diagnostic and statistical manual of mental disorders (DSM-5 ${ }^{\oplus}$ ). Am Psychiatric Pub

23. Eldafrawy $H$, Atef A, Arafa M (1998) Infantile autism in Egyptian children: assessment and clinical correlates. Egypt J Psychiatry 21:58-93

24. El Sady S, El Shoubary A, Hafe N, Mohamed A (2011) Modified preschool language scale, 4th edition. Unpublished Doctoral thesis (MD thesis). Faculty of Medicine, Ain Shams University, Egypt.

25. Ramsay M, Martel C, Porporino M, Zygmuntowicz C (2011) The Montreal Children's Hospital Feeding Scale: a brief bilingual screening tool for identifying feeding problems. Paediatr Child Health 16(3):147-e17. https:// doi.org/10.1093/pch/16.3.147

26. Chlebowski C, Green JA, Barton ML, Fein D (2010) Using the childhood autism rating scale to diagnose autism spectrum disorders. J Autism Dev Disord 40(7):787-799. https://doi.org/10.1007/s10803-009-0926-x

27. Viviers M, Jongh M, Dickonson L, Malan R, Pike T (2020) Parent-reported feeding and swallowing difficulties of children with Autism Spectrum Disorders (aged 3 to 5 years) compared to typically developing peers: a South African study. African Health Sciences. 2020;20(1):524-32.

28. Lukens CT, Linscheid TR (2008) Development and validation of an inventory to assess mealtime behavior problems in children with autism. J Autism Dev Disord 38(2):342-352. https://doi.org/10.1007/s10803-007-0401-5

29. Hudson A, Macdonald M, Blake K (2016) Packing and problematic feeding behaviors in CHARGE syndrome: a qualitative analysis. Int J Pediatr Otorhinolaryngol 82:107-115. https://doi.org/10.1016/j.jporl.2016.01.009

30. Shmaya Y, Eilat-Adar S, Leitner Y, Reif S, Gabis L (2015) Nutritional deficiencies and overweight prevalence among children with autism spectrum disorder. Res Dev Disabil 38:1-6. https://doi.org/10.1016/j.ridd.2 014.11.020

31. Twachtman-Reilly J, Amaral SC, Zebrowski PP (2008) Addressing feeding disorders in children on the autism spectrum in school-based settings: physiological and behavioral issues. Lang Speech Hear Serv Sch 39(4):261272 American Speech-Language-Hearing Association.0161-1461/08/39020261
32. Tomchek SD, Dunn W (2007) Sensory processing in children with and without autism: a comparative study using the short sensory profile. Am J Occup Ther 61(2):190-200. https://doi.org/10.5014/ajot.61.2.190

33. Legge B (2002) Can't eat, won't eat: dietary difficulties and autistic spectrum disorders. Jessica Kingsley Publishers

34. Hill AP, Zuckerman KE, Fombonne E (2015) Obesity and autism. Pediatrics. 136(6):1051-1061. https://doi.org/10.1542/peds.2015-1437

35. Field D, Garland M, Williams K (2003) Correlates of specific childhood feeding problems. J Paediatr Child Health 39(4):299-304. https://doi.org/10.1 046/j.1440-1754.2003.00151.x

36. Williams PG, Dalrymple N, Neal J (2000) Eating habits of children with autism. Pediatr Nurs 26(3):259-264

37. Broder-Fingert S, Brazauskas K, Lindgren K, lannuzzi D, Van Cleave J (2014) Prevalence of overweight and obesity in a large clinical sample of children with autism. Acad Pediatr 14(4):408-414. https://doi.org/10.1016/j.acap.2014. 04.004

38. Evans EW, Must A, Anderson SE, Curtin C, Scampini R, Maslin M, Bandini L (2012) Dietary patterns and body mass index in children with autism and typically developing children. Res Autism Spectr Disord 6(1):399-405. https://doi.org/10.1016/j.rasd.2011.06.014

39. Castro K, Faccioli LS, Baronio D, Gottfried C, Perry IS, Riesgo R (2016) Feeding behavior and dietary intake of male children and adolescents with autism spectrum disorder: a case-control study. Int J Dev Neurosci 53(1):6874. https://doi.org/10.1016/j.ijdevneu.2016.07.003

40. Malhi $P$, Venkatesh $L$, Bharti B, Singhi $P$ (2017) Feeding problems and nutrient intake in children with and without autism: a comparative study. Indian J Pediatr 84(4):283-288. https://doi.org/10.1007/s12098-016-2285-x

41. Baker AE, Lane A, Angley MT, Young RL (2008) The relationship between sensory processing patterns and behavioural responsiveness in autistic disorder: a pilot study. J Autism Dev Disord 38(5):867-875. https://doi.org/1 $0.1007 /$ s10803-007-0459-0

42. Lopez BR, Lincoln AJ, Ozonoff S, Lai Z (2005) Examining the relationship between executive functions and restricted, repetitive symptoms of autistic disorder. J Autism Dev Disord 35(4):445-460. https://doi.org/10.1007/s10803005-5035-x

43. Epstein T, Saltzman-Benaiah J, O'hare A, Goll JC, Tuck S (2008) Associated features of Asperger syndrome and their relationship to parenting stress. Child Care Health Dev 34(4):503-511. https://doi.org/10.1111/j.1365-2214.2 008.00834.x

44. Ernsperger L, Stegen-Hanson T (2004) Just take a bite: easy, effective answers to food aversions and eating challenges! Fut Horizons

45. Groden J, Diller A, Bausman M, Velicer W, Norman G, Cautela J (2001) The development of a stress survey schedule for persons with autism and other developmental disabilities. J Autism Dev Disord 31(2):207-217. https://doi. org/10.1023/A:1010755300436

46. Liu X, Liu J, Xiong X, Yang T, Hou N, Liang X, Chen J, Cheng Q, Li T (2016) Correlation between nutrition and symptoms: nutritional survey of children with autism spectrum disorder in Chongqing, China. Nutrients. 2016;8(5): 294.

47. Johnson CR, Turner K, Stewart PA, Schmidt B, Shui A, Macklin E, Reynolds A, James J, Johnson SL, Courtney PM, Hyman SL (2014) Relationships between feeding problems, behavioral characteristics and nutritional quality in children with ASD. J Autism Dev Disord 44(9):2175-2184. https://doi.org/1 0.1007/s10803-014-2095-9

48. Crasta JE, Benjamin TE, Suresh AP, Alwinesh MT, Kanniappan G, Padankatti SM, Russell PS, Nair MK (2014) Feeding problems among children with autism in a clinical population in India. Indian J Pediatr 81(2):169-172. https://doi.org/10.1007/s12098-014-1630-1

49. Malhi $P$, Venkatesh $L$, Bharti B, Singhi $P$ (2021) Do atypical food preferences in children with autism differ by severity? Indian J Pediatr 88(3):307-307. https://doi.org/10.1007/s12098-020-03534-2

\section{Publisher's Note}

Springer Nature remains neutral with regard to jurisdictional claims in published maps and institutional affiliations. 